\title{
GUIAS DE REPUTAÇÃO RELACIONADOS AO AMBIENTE DE TRABALHO INFLUENCIAM DECISÕES DE INVESTIMENTO?
}

\author{
Daniel José Cardoso da Silva ${ }^{1}$, Ricardo Suave ${ }^{2}$ \\ ${ }^{1}$ danieljcsilva@gmail.com \\ 2ricardosuave@outlook. com
}

\section{Resumo}

Como forma de assegurar a continuidade, as empresas buscam otimizar suas fontes de financiamento que lhes garantam funding para a operacionalização dos seus negócios. A imagem frente ao mercado é um ativo que precisa ser devidamente comunicado para a efetividade das suas estratégias. Os financiadores/investidores, por sua vez, buscam informações que lhes auxiliem na tomada de decisão de investimentos. De maneira cada vez mais frequente, guias reputacionais se apresentam como supostos subsídios para o mercado. $\mathrm{Na}$ presente pesquisa, objetivou-se verificar se a presença ou não nesses referidos guias, especialmente em guias sobre a qualidade do ambiente de trabalho proporcionada aos trabalhadores, interfere na decisão de investidores. A estratégia de pesquisa se baseou no uso de um experimento com abordagem between-subjects, em que houve a manipulação de um fator independente em dois níveis, nomeadamente, a presença ou não em guias reputacionais. A pesquisa foi aplicada com estudantes de graduação de universidades públicas, de maneira voluntária, e não houve qualquer espécie de incentivo para a participação. Para análise estatística, utilizou-se a Anacor como técnica exploratória e Regressão Logística Multinomial como técnica confirmatória. Os resultados evidenciaram que a presença em guias reputacionais não influencia decisões de investimento, o que sugere que investidores razoavelmente bem informados acerca de possíveis organizações a se investir não levam tal informação como fator decisivo para investir.

Palavras-chave: Guias reputacionais. Melhores para se trabalhar. Decisão de investimento. Experimento.

\section{DO REPUTATION GUIDES RELATED TO WORK ENVIRONMENT INFLUENCE INVESTMENT DECISIONS?}

\section{Abstract}

As a way to ensure survival, companies seek to optimize their sources of funding to guarantee resources for the operation of their businesses. The image to the market is an asset that needs to be properly communicated to the effectiveness of firm strategies. Funders / investors, on the other hand, are looking for information to assist them in making investment decisions. Often, reputational guides present themselves as theoretical subsidies for the market. In the present study, the aim was to verify whether the presence or not in these guides, especially in guides on the quality of the work environment provided to workers, interferes in the investors' decisions. The research strategy was based on the use of an experiment with a between-subjects approach, in which there was the manipulation of an independent factor, namely, the presence or not of reputational guides. The research was applied with undergraduate students from public universities, on a voluntary basis, and there was no incentive for participation. For statistical analysis, Correspondence analysis was used as exploratory technique and Multinomial Logistic Regression as confirmatory technique. The results showed that the presence in guides does not 
influence investment decisions, which suggests that investors reasonably well informed about possible organizations to invest do not take such information as a decisive factor to invest.

Keywords: Reputational guides. Best firms to work. Investment decision. Experiment.

\section{Introdução}

Com periodicidade, geralmente anual, são publicados guias de reputação de empresas do tipo: melhores para se trabalhar, maiores e melhores, as 100 melhores, melhores por setor, empresas mais sustentáveis, etc. Autores como Orlitzky et al. (2003) reconhecem a importância desse tipo de guia. Estudos como Fulmer et al. (2003), Junqueira et al. (2007), Lima e Corrar (2009) e Berdejo e Guerreiro (2009) demonstram em seus achados que o desempenho financeiro das empresas listadas como melhores para se trabalhar é superior às demais. Embora estudos como o de Silva et al. (2013) divirjam de resultados que apontam diferenciação de desempenho de empresas listadas nesses guias, é inegável que esse tipo de publicação é cada vez mais popular. Além disso, a presença das empresas nas listagens de melhores práticas com empregados (MPE), na visão de Barney (1991), pode ser considerado um recurso idiossincrático e difícil de ser imitado, o que leva a considerar este recurso como uma fonte de vantagem competitiva sustentável (BERDEJO; GUERREIRO, 2009).

Uma reflexão que se pode fazer se refere à utilidade prática dos guias reputacionais. Isso porque analistas de mercado utilizam de ferramentas mais sofisticadas para a sua tomada de decisões. Seriam então apenas mais um instrumento de marketing e persuasão utilizado pelas firmas para se legitimarem junto ao mercado e sociedade em geral? Neste artigo, pretende-se evidenciar se o fato de figurar em um guia de melhores empresas para se trabalhar pode influenciar investidores razoavelmente informados em um contexto de tomada de decisão de investimento.

Se por um lado, analistas profissionais estão munidos de ferramentas sofisticadas para basear suas decisões, os investidores não profissionais, pelo outro, possuem menor contato com tais ferramentas. Consideram-se como características desse tipo de investidor a aversão ao risco (KAHNEMAN; TVERSKY, 1979) e maior confiança em investir quando munido de informações positivas (SILVA et al, 2010). Contudo, argumenta-se que tais investidores tendem a ignorar as informações contidas nesses guias, uma vez que possuem como foco a lucratividade. Tal argumento pode ser baseado na Balance Theory (BATISTA, 2014), em que os investidores não julgam tais guias para decisão de investimento como fonte de informação relevante ou confiável.

Portanto, a questão de pesquisa que norteia o presente estudo é a seguinte: Afinal, estar listada em um guia de reputação beneficia significantemente a imagem da empresa, influenciando a tomada de decisão do investidor? Dessa maneira, objetiva-se com o presente estudo verificar se a presença ou não em guias de melhores práticas com empregados pode influenciar investidores em sua tomada de decisão.

Justifica-se o presente estudo pela relevância da comunicação das empresas com seus clientes/investidores e as heurísticas envolvidas na tomada de decisão de investimento. Enquanto investidores profissionais são bem municiados de informações, investidores com menor poder financeiro, devido a assimetria informacional (CHENG; IOANNOU; SERAFEIM, 2014; EASLEY; HVIDKJAER; O'HARA, 2002; EASLEY et al., 1996) existente no mercado de ações, dispõem de meios com inferior qualidade e diversidade para tomarem suas decisões. Deste modo, guias reputacionais, de alguma forma, podem suprir de informações investidores pouco ou razoavelmente informados.

O proceder metodológico deste trabalho pauta-se numa revisão não exaustiva da literatura. Os trabalhos revistos foram selecionados pela sua significância em relação ao tema, 
sua coerência científica e sua capacidade em explicar os efeitos encontrados no experimento e suportar possibilidades inter-relacionais. Esta revisão de literatura é apresentada logo após a introdução, seguida dos procedimentos metodológicos do experimento e resultados com teste da hipótese do trabalho. Finaliza-se com a apresentação das conclusões, limitações e sugestões de pesquisas futuras.

\section{Referencial Teórico e Hipóteses}

\subsection{Teorias de Comunicação e Persuasão}

A comunicação é indispensável para a sobrevivência dos seres humanos e para a formação e coesão de comunidades, sociedades e culturas. Entre outras razões, também para satisfazer necessidades, conforme preconizado por Maslow $(1943,1954)$. Quando alguém tem a iniciativa de comunicar, obviamente tem alguma intenção. Só é despendido esforço quando isso leva a algum objetivo e, por isso, a comunicação intencional existe quando se deseja atingir determinado fim, mesmo que seja tão somente a manutenção da própria comunicação. A convergência de um vasto tipo de fenômenos para debaixo do guarda-chuva da comunicação tem origem na elasticidade e flexibilidade do conceito. A raiz etimológica da palavra comunicação é a palavra latina communicatione, que, por sua vez, deriva da palavra commune, ou seja, comum. Communicatione significa, em latim, participar, pôr em comum ou ação comum. Portanto, comunicar é, etimologicamente, relacionar seres viventes e, normalmente, conscientes (seres humanos), tornar alguma coisa comum entre esses seres, seja essa coisa uma informação, uma experiência, uma sensação, uma emoção, etc (SOUSA, 2003).

$\mathrm{Na}$ contemporaneidade as pessoas podem adquirir muita informação sobre o mundo e as personalidades implicadas nos acontecimentos. Na mídia, conjunto dos diversos meios de comunicação, com a finalidade de transmitir informações e conteúdos variados, apresentam-se decisões que afetam a todos, personalidades, ideias e ideologias. É um lócus em que se aborda política, economia, ciências, educação, trabalho, leis, arte, sociedade, culturas, pessoas, lugares, ideias etc. A riqueza de informação permite a construção de conhecimentos sólidos sobre a realidade por aqueles que a souberem aproveitar.

Segundo Brown (1963), as tentativas de modificar a opinião dos outros antecedem a própria linguagem escrita, sendo propiciadas pelo "dom da palavra". Com esta surge o poder de manipular, ou persuadir pessoas, sem o recurso obrigatório à força física. De modo que, antes de falar, é improvável que as pessoas possuíssem opiniões a serem modificadas. Ainda segundo aquele autor, sem prejuízo para todos os demais recursos de comunicação disponíveis na atualidade, a violência direta, ou ameaça dela, podem produzir submissão à vontade de um outro indivíduo ou grupo, porém os pensamentos são criados e modificados, sobretudo pela palavra escrita. De maneira semelhante, em seu trabalho seminal sobre comunicação, Dawkins e Krebs (1978) argumentam que os sinalizadores (ou emissores) são mais propensos a manipular do que a informar os receptores.

Uma característica dos estudos da persuasão no Brasil, na área de comunicação, é a ênfase nos trabalhos de linguística, cuja base teórica parte da análise de discursos, semiótica, retórica, entre outros. Dois filósofos gregos podem ser considerados como originadores dos estudos sobre persuasão: Platão e Aristóteles. O primeiro descrevia a realidade como uma interpretação das formas abstratas dos objetos que existem nas mentes das pessoas. Já Aristóteles entendia que a representação mental do objeto era derivada da concreta observação de suas características reais. Fica clara a maior influência de Aristóteles no desenvolvimento dos estudos de persuasão, uma vez que estão associados aos de atitude, palavra que tem suas origens ligadas a fontes físicas ou psicológicas (BATISTA, 2014). 
Podem ser identificados quatro principais abordagens teóricas no desenvolvimento dos estudos de persuasão, conforme Quadro 1.

Quadro 1 - Principais abordagens em estudos de persuasão

\begin{tabular}{|l|l|}
\hline Teoria do aprendizado & $\begin{array}{l}\text { Baseada na visão behaviorista de estímulo resposta, os estudos nesse foco observam } \\
\text { como a atitude poderia ser mudada por prêmio ou punição. }\end{array}$ \\
\hline Foco Perceptual & $\begin{array}{l}\text { A proposta desta linha de pensamento considera como aspecto mais relevante o } \\
\text { significado da mensagem para o indivíduo }\end{array}$ \\
\hline Teoria Funcionalista & $\begin{array}{l}\text { Preconiza que a persuasão (mudança de atitude) só acontece quando a mensagem é } \\
\text { relevante, pessoal ou socialmente para o indivíduo, e consegue alterar este aspecto } \\
\text { central da atitude pela modificação de conhecimentos anteriores, ou adicionando } \\
\text { novos. }\end{array}$ \\
\hline Teoria da Consistência & $\begin{array}{l}\text { Esta defende que as mudanças, ou não de atitudes são ferramentas mentais do } \\
\text { indivíduo para ajustar uma atitude pessoal interna e manter a harmonia do sistema. }\end{array}$ \\
\hline
\end{tabular}

Fonte: Extraído e elaborado a partir de Batista (2014).

A Balance Theory, relacionada à resistência à persuasão por parte do receptor e possíveis efeitos antecipatórios, preconiza que o equilíbrio só é atingido se os conceitos são relevantes e se alinham com os valores de quem recebe a informação (BATISTA, 2014). A seguir, como exemplo, a Figura 1 ilustra uma estratégia de anulação de um rumor ou boato. Outro aspecto da manutenção desse equilíbrio e aceitação dos conceitos, observando-se, por outro lado, se a fonte da informação goza de credibilidade junto ao receptor. Assim, se não se estabelecer a harmonia nessa Triad, a comunicação pode se tornar inócua.

Figura 1 - Triad do equilíbrio

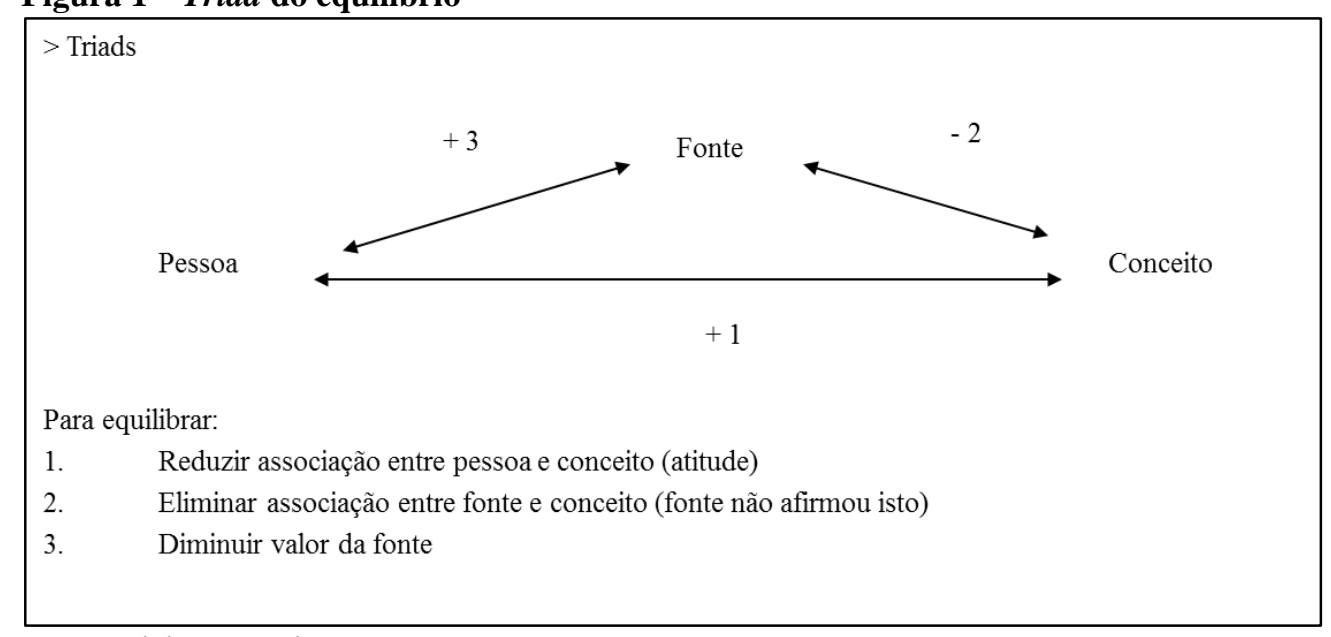

Fonte: Elaboração dos autores.

Essa teoria foi desenvolvida por Fritz Heider na década de 1950. Em sua análise de unidades cognitivas balanceadas, segundo Cartwright e Harary (1956), Heider categoriza dois tipos principais de relações. A primeira se refere a atitudes, ou da relação de gostar ou de avaliar (no sentido de aprovação). A segunda se refere à formação de unidade cognitiva, a partir de relações específicas como semelhança, posse, causalidade, proximidade ou pertencer. Então, um 'estado balanceado' ocorre sob certas combinações das referidas relações entre duas entidades, por exemplo, e deve ser positiva ou negativa em ambos os casos.

Mas, se a comunicação social contribuiu para revolucionar o mundo, é porque tem efeitos. Um componente importante da teoria da comunicação é edificada, mais precisamente, em torno dos efeitos da comunicação social, procurando responder a questões como: Quais são os efeitos da comunicação social e a que nível se produzem (individual, social, cultural, civilizacional, histórico)? O que leva a outros questionamentos como: Até que ponto é possível 
a um emissor planejar o efeito que quer produzir ao comunicar e até que ponto é que o resultado ocorre conforme o planejado? Ou então: Que instâncias mediam os efeitos da comunicação social, e quais os fatores, comunicacionais e não comunicacionais, que interferem nessa mediação? Qual é a capacidade mediadora desses fatores? (SOUZA; GUEDES, 2007).

No geral, as diferentes teorias dos efeitos, em particular as que se fundamentam em pesquisas empíricas, buscam mostrar que as mídias têm maior impacto ao nível das percepções da realidade e das cognições do que ao nível da mudança de atitudes e comportamentos e que os efeitos da mesma são diferentes consoante o receptor e o contexto da recepção. A seguir, apresenta-se no Quadro 2 um resumo das teorias mais popularizadas em relação à comunicação e seus supostos efeitos.

\section{Quadro 2 - Resumo das principais teorias em comunicação}

\begin{tabular}{|c|c|}
\hline $\begin{array}{l}\text { A Teoria das Balas } \\
\text { Mágicas ou da Agulha } \\
\text { Hipodérmica }\end{array}$ & $\begin{array}{l}\text { As imagens sugeridas por ambas as denominações ("Balas Mágicas "ou "Agulha } \\
\text { Hipodérmica") pretendem traduzir, metaforicamente, que as pessoas apresentam o } \\
\text { mesmo comportamento mecânico (a resposta) ao serem atingidas pelas mensagens } \\
\text { mediáticas (o estímulo). Daí as "balas mágicas"(pois só "balas mágicas" atingem } \\
\text { todos da mesma maneira) ou a "agulha hipodérmica"(pois os efeitos dos } \\
\text { medicamentos injetados tendem a ser os mesmos nas diferentes pessoas). No modelo } \\
\text { das "Balas Mágicas", a comunicação é, assim, vista, sobretudo, como um processo } \\
\text { reativo, enquanto a sociedade é avaliada como sendo constituída por indivíduos } \\
\text { aglomerados numa massa uniforme e passiva. }\end{array}$ \\
\hline $\begin{array}{l}\text { As teorias do Two-Step } \\
\text { e do Multi- Step Flow } \\
\text { of Communication }\end{array}$ & $\begin{array}{l}\text { Defendem que os meios de comunicação estão longe de ter um poder quase ilimitado } \\
\text { sobre as pessoas. Pelo contrário, há que contar com um mecanismo conhecido como } \\
\text { exposição seletiva e há ainda que contar com a influência de determinados agentes } \\
\text { mediadores entre a mídia e as pessoas (fluxo de comunicação em duas etapas). }\end{array}$ \\
\hline $\begin{array}{l}\text { Estud } \\
\text { persu }\end{array}$ & $\begin{array}{l}\text { A mesma mensagem, consoante o emissor seja mais ou menos credível aos olhos do } \\
\text { receptor, tende a ser mais ou menos persuasiva. }\end{array}$ \\
\hline $\begin{array}{l}\text { A Teoria do Agenda- } \\
\text { Setting }\end{array}$ & $\begin{array}{l}\text { A Teoria do Agenda-Setting, ou do Agendamento, destaca que os meios de } \\
\text { comunicação têm a capacidade (não intencional nem exclusiva) de agendar temas } \\
\text { que são objeto de debate público em cada momento. }\end{array}$ \\
\hline $\begin{array}{l}\text { A Teor } \\
\text { Temati }\end{array}$ & $\begin{array}{l}\text { so de definição, estabelecimento e reconhecimento público } \\
\text { os através da comunicação social. }\end{array}$ \\
\hline $\begin{array}{l}\text { A Teoria da Espiral do } \\
\text { Silêncio }\end{array}$ & $\begin{array}{l}\text { O pressuposto da Teoria da Espiral do Silêncio é o seguinte: as pessoas temem o } \\
\text { isolamento, buscam a integração social e gostam de ser populares; por isso, as } \\
\text { pessoas têm de permanecer atentas às opiniões e aos comportamentos maioritários e } \\
\text { procuram expressar-se dentro dos parâmetros da maioria. }\end{array}$ \\
\hline $\begin{array}{l}\text { A Teoria dos Usos e } \\
\text { Gratificações }\end{array}$ & $\begin{array}{l}\text { Contra as hipóteses e teorias dos efeitos poderosos da comunicação social, a Teoria } \\
\text { dos Usos e Gratificações pressupõe uma relativização do poder dos meios de } \\
\text { comunicação sobre as pessoas e a sociedade. }\end{array}$ \\
\hline $\begin{array}{l}\text { A Teoria das } \\
\text { Diferenças de } \\
\text { Conhecimento } \\
\text { (Knowledge Gap) }\end{array}$ & $\begin{array}{l}\text { Levanta a hipótese de que entre os principais efeitos da comunicação social a longo } \\
\text { prazo se inscreve a capacidade de diferenciar "classes sociais" em função do } \\
\text { conhecimento. As pessoas educacionalmente mais favorecidas reúnem } \\
\text { potencialmente condições para absorver mais informação e para melhor integrar essa } \\
\text { informação nas suas estruturas cognitivas. }\end{array}$ \\
\hline $\begin{array}{l}\text { A Tec } \\
\text { Deper }\end{array}$ & $\begin{array}{l}\text { As bases do modelo da dependência do sistema de meios de comunicação, procura } \\
\text { explicar a centralidade dos meios de comunicação social na sociedade, quer ao nível } \\
\text { macrossocial, quer ao nível individual. Assim, a relação entre a sociedade, o público } \\
\text { e os meios, modela os efeitos destes últimos. }\end{array}$ \\
\hline $\begin{array}{l}\text { Teoria do Cultivo ou } \\
\text { da Incubação }\end{array}$ & $\begin{array}{l}\text { A magnitude e a constância da presença de determinados temas e mensagens no } \\
\text { conteúdo da mídia podem gerar a incubação de ideias dissonantes da realidade, sendo } \\
\text { o grau de desvio dessas ideias tanto maior quanto maior for a dissonância existente } \\
\text { entre a realidade e as suas representações midiáticas. }\end{array}$ \\
\hline a socialização & $\begin{array}{l}\text { Os meios competem com a família, a escola, as relações informais, os partidos } \\
\text { políticos, o governo, etc. enquanto agentes de socialização. }\end{array}$ \\
\hline $\begin{array}{l}\text { As teorias da } \\
\text { construção social da } \\
\text { realidade }\end{array}$ & $\begin{array}{l}\text { A perspectiva central do conceito é a de que toda a realidade é socialmente } \\
\text { construída, dia a dia, pelas práticas individuais e sociais, o que conduz a uma }\end{array}$ \\
\hline
\end{tabular}


\begin{tabular}{|l|l|}
\hline & $\begin{array}{l}\text { permanente redefinição e renegociação das regras, normas, significados e símbolos } \\
\text { sociais. }\end{array}$ \\
\hline
\end{tabular}

Fonte: elaborado a partir de Sousa (2003).

Pode-se abstrair, a partir do Quadro 2, que a comunicação é algo presente no cotidiano das pessoas e que é um instrumento utilizado por profissionais que objetivam transmitir mensagens, ideias, opiniões entre outros. Esclarecedora é a afirmação de Batista, Cavalheiro e Leite (2008) de que, entre outros, um papel relevante da mídia é sua função de referência, ou seja, de ressaltar quem os indivíduos devem considerar como modelos ou padrões normativos de comportamento. Ressaltam ainda que este aspecto é de alta relevância no atual momento da sociedade, uma vez que contatos diretos estão sendo "substituídos" pelos contatos realizados de forma virtual, fato que afeta os conceitos do valor da proximidade física que perduraram por longo tempo.

Um outro argumento que se pode levar em consideração é o que é produzido pelo fenômeno da "exposição e preferência", que segundo Zajonc (1968) pode ser entendido da seguinte maneira: "A mera exposição repetida do indivíduo a um estímulo é condição suficiente para intensificar sua atitude em favor desse estímulo". Uma prova que corrobora a hipótese de exposição é correlacional e sugere que as coisas ou acontecimentos com uma alta frequência de aparecimento no meio (isto é, maior exposição) recebem classificações mais favoráveis do que aquelas com uma probabilidade inferior de aparecimento (HARISSON, 1972). Outros estudos efetuados na área de motivação do consumidor, como o de Becknell, Wilson e Baird (1963) evidenciaram que seus sujeitos tinham reações cada vez mais favoráveis a "nomes de marcas" forjados pelos investigadores, depois que esses nomes lhes foram mostrados repetidas vezes.

A partir desse ponto não é difícil imaginar que em um contexto de alta competitividade como o que se verifica atualmente no mercado cada dia mais global, as empresas procuram comunicar aos clientes ou potenciais clientes, a maior quantidade de vezes quanto possível e pelos mais diversos meios midiáticos, as informações que lhe são mais favoráveis e que propiciarão a formação da imagem mais positiva e alinhada com os valores já consolidados pelo senso comum da sociedade (ambiental e socialmente responsável, entre outros) o que pode também ser explicado, como argumenta Dias Filho (2009) pela teoria da legitimidade.

\subsection{Guias reputacionais de empresas}

Na presente pesquisa, argumenta-se que a veiculação em guias reputacionais é uma das formas que as empresas se utilizam para difundir informações favoráveis a seu respeito para melhorar sua imagem, até mesmo para manipular a visão dos stakeholders sobre elas. Tais guias reputacionais, geralmente, são realizados pela imprensa especializada ou estudantes de negócios e envolve a análise de aspectos concernentes ao índice. Entre os tipos de informações analisadas, podem constar pesquisas com funcionários, demonstrações financeiras, opinião pública, entre outras. De acordo com Orlitzky, Schmidt e Rynes (2003), relativo a índices de desempenho social corporativo, tais índices de reputação são baseados no pressuposto de que esse desempenho reputacional reflete bem os valores e comportamentos sociais da empresa. Dessa maneira, independente do que buscam demonstrar, espera-se que esses índices sejam uma representação mais próxima o possível da realidade das empresas estudadas.

Respectivo aos guias de melhores empresas para se trabalhar, cujo foco é do presente trabalho, o estudo de Berdejo e Guerreiro (2009, p. 89) define como "estudos que visam identificar os empregadores preferidos dos empregados dentre empresas e organizações que se apresentam voluntariamente com o propósito de classificar o empregador". Os autores citam que são fontes de informação as práticas de recursos humanos (RH), além de pesquisas de opinião com empregados acerca das práticas de RH da empresa, cultura, liderança, 
oportunidades, entre outros. Destaca-se que no conceito apresentado pelos autores, estes citam que tais guias são compostos de empresas que se apresentam voluntariamente, ou seja, são empresas que se preocupam em passar determinada impressão aos leitores de tais guias.

Outro aspecto importante referente a tais guias se refere à grande circulação. Guias como esses, seja em países desenvolvidos como Estados Unidos, ou em desenvolvimento, como o Brasil, possuem grande abrangência em termos de publicação. De tal modo, essa é mais uma razão para que as empresas queiram participar de tais ranqueamentos. Conforme Orlitzky, Schmidt e Rynes (2003), pela perspectiva da reputação, tais guias se configuram como oportunidade de comunicação das empresas com partes externas e podem ajudar a construir uma imagem positiva com clientes, investidores e bancos. Além disso, servem como um sinal para avaliações da companhia e possibilidade de acesso a capital, atrair melhores empregados e melhorar seu capital intelectual, se constituindo numa clara mensagem aos mais diversos Stakeholders, o que levanta uma questão importante referente ao papel das mensagens. Componentes da mensagem como humor, alertas e selos de aprovação de ONGS, por exemplo, podem ter papéis associados com a menor persuasão, dependendo da quantidade de processamento que a mensagem desencadeia no indivíduo (BATISTA, 2014).

Todavia, existem estudos que comparam tais rankings e elencam alguns problemas envolvidos. Por exemplo, Fombrun (1998), além de verificar os principais responsáveis pela elaboração desses guias e suas metodologias, destaca que tendem a ser enviesados em termos de amostras de companhias selecionadas e audiências a que são direcionados. Fryxell e Wang (1994) mencionam que o guia da Fortune está altamente baseado em medidas financeiras, até mesmo itens como comunidade e responsabilidade ambiental envolvem a percepção dos avaliadores acerca do potencial financeiro das empresas.

Dessa maneira, a hipótese do trabalho se baseia em alguns dos principais argumentos dessa revisão. O primeiro deles é que as empresas que participam desses guias o fazem de maneira voluntária. Outro argumento são os problemas que estudos anteriores identificaram em tais guias, nomeadamente, problemas de mensuração e seleção que podem produzir resultados duvidosos. Por fim, Silva et al. (2013) encontraram que não há diferença significativa de desempenho entre empresas listadas e não listadas nesses guias, o que tornaria o fato de figurar entre as melhores indiferente para os acionistas. Portanto, pode-se inferir que, devido aos problemas de metodologia desses guias, analistas e outros investidores profissionais não utilizam tais guias como aporte informacional, além disso, pela participação de caráter voluntário, a presença nesses guias pode ser associada a uma intenção de promoção da reputação. A seguir, formula-se a hipótese do trabalho:

H1: O fato de uma empresa figurar em um guia reputacional não influencia o investidor, a ponto de promover aumentos estatisticamente significantes em sua intenção de investimento.

Nesse caso, considerando a Balance Theory, um estado não balanceado entre investidor, uma empresa e a listagem dessa empresa em guia reputacional pode desencadear na concepção, por parte do investidor, de que a listagem dessa empresa em guia não se constitua em informação decisiva para a decisão de investir em uma companhia.

Em termos de objetivo, o presente estudo se assemelha a Elliott et al. (2014). O referido estudo teve por objetivo verificar se os participantes do experimento alteravam sua propensão de investimento na empresa ao avaliarem seu desempenho social corporativo. Contudo, estudos anteriores que abordam a temática de listagem em guias buscam relacionar a presença das empresas nesses guias com o desempenho (FULMER; GERHART; SCOTT, 2003; LIMA; CORRAR, 2010). Outro aspecto é que tais trabalhos consideram o desempenho social corporativo, enquanto este se utiliza da informação de figurar no guia de melhores empresas 
para se trabalhar no país como proxy para guia reputacional. Apresenta-se a seguir a metodologia empregada para o teste da hipótese do trabalho.

\section{Metodologia do Experimento}

\subsection{Design e Participantes}

Experimentos na contabilidade financeira podem ser usados para testar novas políticas contábeis antes mesmo de serem aplicadas (KACHELMEIER; KING, 2002). Sob tal perspectiva, utilizou-se do método experimental para verificar a influência da presença das empresas em guias reputacionais relacionados ao ambiente de trabalho. Para testar as hipóteses, realizou-se um experimento com uma abordagem between-subjects, em que manipulamos apenas um fator independente em dois níveis. $\mathrm{O}$ fator que foi manipulado, nomeadamente, foi a listagem ou não da companhia em guia de melhores empresas para se trabalhar.

Como proxies para investidores razoavelmente informados, 99 estudantes de graduação, em vários estágios de formação (a partir do $4^{\circ}$ semestre), matriculados em cursos de contabilidade e atuária em escolas de negócios de duas Universidades públicas situadas no Estado de São Paulo, participaram do experimento. De acordo com Libby, Bloomfield e Nelson (2002), a utilização de participantes mais sofisticados é mais difícil de se conseguir e pode ser utilizada quando a questão de pesquisa o exige, portanto, devido à natureza da atividade do experimento, a utilização de estudantes é considerada adequada. Os participantes realizaram o experimento durante uma aula, sem aviso prévio, dentro da programação normal das aulas (turmas matriculadas nos turnos matutino e noturno) e o fizeram de forma espontânea, sem receber nenhum tipo de incentivo para executar o experimento. A aplicação do experimento ocorreu entre os dias 27 de outubro a 7 de novembro de 2016, com uma duração média de 20 minutos por participante para a realização da pesquisa.

\subsection{Procedimentos}

A aplicação do experimento teve início com os participantes já sentados em seus lugares habituais. Depois da aula iniciada, de maneira aleatória, os pesquisadores realizaram a distribuição dos questionários. Metade dos participantes recebeu o questionário com o tratamento e a outra metade sem tratamento. Ressalte-se que os participantes não possuíam conhecimento da manipulação realizada nos questionários.

Em seguida os respondentes leram um pequeno texto em que foram solicitados a supor que tivessem recebido uma herança (ELLIOT et al., 2014) de um parente distante no valor de $\mathrm{R} \$ 100.000,00$ e, que ao procurar um banco, foram orientados a aplicar parte dessa suposta herança em ações de uma empresa. Na continuidade do texto, constavam informações como controlador do capital, setor da firma, faturamento no ano de 2015, taxa de crescimento em relação ao ano anterior, lucro e média de lucratividade da entidade nos últimos 5 anos. Foram acrescentadas informações positivas acerca da confiabilidade das demonstrações financeiras, da reputação da firma no mercado e da preocupação em conciliar o seu desenvolvimento econômico com a preservação do meio ambiente. Ressaltava-se que, apesar de uma menor escala, os balanços parciais sugeriam uma tendência de lucro para 2016, considerando-se o cenário de crise da economia brasileira. Os dois tipos de questionários entregues aos participantes continham um texto exatamente igual, exceto que no grupo de tratamento era adicionada ao final da narrativa a seguinte frase: "Por fim, nos últimos 4 anos a empresa tem sido listada em guias das melhores empresas para se trabalhar no Brasil". O instrumento de pesquisa consta no Apêndice. 
O questionário utilizado no experimento possui 10 questões. A primeira delas perguntava ao participante qual o percentual de sua suposta herança que ele estaria disposto a investir em ações daquela empresa. A segunda questão objetivava definir o perfil de investidor do respondente (se conservador, moderado ou agressivo) ao perguntar qual o tipo de aplicação que mais lhe agradava. As opções oferecidas eram a poupança (conservador), CDB e renda fixa (moderado), ações e derivativos (agressivo) e, por fim, uma alternativa em que os participantes poderiam declarar que não tinham preferência por nenhum tipo de investimento financeiro.

As perguntas de 3 a 6 buscaram categorizar o respondente em relação a aspectos demográficos: sexo, faixa etária e área de formação. As questões 7 e 8 , formatadas em escala likert, almejavam capturar as percepções dos participantes sobre a empresa com base nas informações que lhe foram fornecidas (Responsabilidade socioambiental e confiabilidade). As questões 9 e 10 foram utilizadas com o intuito de checar a efetividade da manipulação do experimento. A descrição das variáveis é apresentada no Quadro 3.

\subsection{Critérios para análises}

De maneira que as variáveis de interesse e explicativas são qualitativas, não se utilizou do artifício de transformação arbitrária dos resultados para médias (FÁVERO; BELFIORE, 2015). Dessa forma, a checagem da manipulação do experimento foi obtida com teste $X^{2}$ a partir de tabelas de frequência absoluta, utilizadas na ANACOR. Para o teste de hipótese empregou-se regressão logística multinomial, dado que a variável dependente é qualitativa e possui mais de duas categorias para respostas. Na sequência, apresentam-se as variáveis utilizadas para a realização deste experimento.

Quadro 3 - Descrição das variáveis

\begin{tabular}{|c|c|c|}
\hline Nome da Variável & Descrição & Tipo de Efeito \\
\hline \multicolumn{3}{|c|}{ Variável Dependente } \\
\hline Percentual de investimento & $\begin{array}{l}\text { Resposta à pergunta Opção de percentual de investimento do } \\
\text { respondente. }\end{array}$ & \\
\hline \multicolumn{3}{|c|}{ Variáveis Independentes } \\
\hline $\begin{array}{l}\text { Listagem no Guia } \\
\text { (Manipulação) }\end{array}$ & $\begin{array}{l}\text { Empresa que em sua descrição, possui (1) ou não (0) a } \\
\text { informação adicional de constar em um Guia de Reputação. }\end{array}$ & Protocolo \\
\hline Perfil do Investidor & $\begin{array}{l}\text { Formada pela resposta à pergunta: Qual o seu tipo de } \\
\text { aplicação preferido? } \\
\text { O resultado seria uma proxy do grau de aceitação de risco, } \\
\text { podendo ser: Conservador, Moderado, Agressivo e } \\
\text { ultraconservador. Optou-se por essa estratégia de extrema } \\
\text { simplificação por uma questão operacional, uma vez que é } \\
\text { reducionista em relação ao exige a resolução CVM } 539 \text {. }\end{array}$ & Individual \\
\hline Sexo & Indica o sexo do respondente & Individual \\
\hline Idade & Indica a faixa etária do respondente & Individual \\
\hline Escolaridade & Indica o nível de escolaridade do respondente & Individual \\
\hline Formação & Indica a área do conhecimento da formação do respondente & Individual \\
\hline $\begin{array}{l}\text { Responsabilidade } \\
\text { Socioambiental }\end{array}$ & $\begin{array}{l}\text { Resposta à pergunta: A empresa tem responsabilidade } \\
\text { socioambiental. }\end{array}$ & Protocolo \\
\hline $\begin{array}{l}\text { Imagem de confiabilidade } \\
\text { da empresa }\end{array}$ & Resposta à pergunta: A empresa é confiável? & Protocolo \\
\hline Responsabilidade Fiscal & $\begin{array}{l}\text { Resposta à pergunta: A empresa tem responsabilidade fiscal? } \\
\text { *Em nenhum dos dois textos apresentados aos respondentes, } \\
\text { foi mencionado nada a respeito da responsabilidade fiscal da } \\
\text { empresa. }\end{array}$ & Protocolo \\
\hline $\begin{array}{l}\text { Impressão do respondente } \\
\text { a respeito de se trabalhar } \\
\text { na empresa da narrativa. }\end{array}$ & $\begin{array}{l}\text { Resposta à pergunta: A empresa é boa para se trabalhar? } \\
\text { Espera-se que a média de respostas para aqueles respondentes } \\
\text { que receberam a informação de que a empresa foi listada }\end{array}$ & $\begin{array}{c}\text { Protocolo } \\
\text { (manipulation } \\
\text { check) }\end{array}$ \\
\hline
\end{tabular}


entre as melhores para se trabalhar no país seja maior que a do grupo sem tratamento.

\section{Análise dos Resultados}

\subsection{Estatísticas Descritivas}

Os participantes do experimento compuseram uma amostra que apresentava as seguintes características. Aproximadamente $46 \%$ dos participantes eram do sexo feminino, $81 \%$ com idade entre 18 e 25 anos, $88 \%$ possuíam nível superior incompleto (já esperado, devido ao perfil dos participantes), e com formação predominantemente em contabilidade $(72 \%)$ e atuária (21\%). Além dessas características, evidencia-se na Tabela 1 a quantidade de participantes ao qual foram designados questionários com tratamento e as frequências absoluta e acumulada para os níveis de investimento. Tais frequências e testes de $X^{2}$ foram gerados a partir da técnica estatística ANACOR.

Tabela 1 - Frequências da variável dependente e de tratamento

\begin{tabular}{l|c|c|c|c|c}
\hline $\begin{array}{l}\text { Presença em } \\
\text { Guia }\end{array}$ Reputação & \multicolumn{5}{|c}{ Percentual aplicado pelo respondente } \\
\cline { 2 - 6 } & $0 \%$ & $25 \%$ & $50 \%$ & $75 \%$ & Total \\
\hline Não Listada & 5 & 37 & 5 & 2 & $\mathbf{4 9}$ \\
\hline Listada & 6 & 36 & 8 & 2 & $\mathbf{5 0}$ \\
\hline Total & 11 & 73 & 13 & $\mathbf{9 9}$ \\
\hline \multicolumn{7}{r}{} \\
\hline
\end{tabular}

Nota: nenhum dos participantes optou por aplicar $100 \%$ da herança.

A partir do resultado do teste $\mathcal{X}^{2}$ fornecido pela tabela de frequência absoluta para o par de variáveis, pode-se afirmar, para um nível de significância de 5\% e para 3 graus de liberdade, que não existe associação estatisticamente significante entre as variáveis Presença em Guia e Reputacional Aplicado pelo Respondente. O que se pode inferir a partir desses resultados é que o fato de a empresa estar listada em guia não foi relevante para o investidor em sua tomada de decisão. Por exemplo, em caso de companhia listada, ao supor que o resultado do teste fosse significante, o percentual aplicado seria estatisticamente superior ao aplicado em companhias não listadas.

Também foram realizados testes $\chi^{2}$ a partir de tabelas de frequência absoluta das variáveis sexo, idade e perfil de investidor em relação à variável de interesse (Percentual aplicado pelo respondente). Em nenhum dos testes foi verificada diferença estatisticamente significante, o que pode ser explicado pela homogeneidade da amostra.

\subsection{Checagem da Manipulação}

Objetivando verificar a efetividade da manipulação, foi incluída no mesmo instrumento a pergunta 10 (vide Apêndice). A mesma teve por objetivo verificar se os respondentes do grupo de tratamento realmente perceberam o fato da suposta ter figurado no guia de melhores empresas para se trabalhar no país (MANDEL; JOHNSON, 2002; PERDUE; SUMMERS, 1986; ELLIOTT et al., 2014). Na Tabela 2 se observam os resultados para este teste.

Tabela 2 - Frequências da variável dependente e checagem de manipulação

\begin{tabular}{l|c|c|c|c|c|c}
\hline $\begin{array}{l}\text { Presença em } \\
\text { Guia } \\
\text { Reputação de }\end{array}$ & \multicolumn{6}{|c}{ Empresa boa para se trabalhar segundo o respondente } \\
\cline { 2 - 7 } & $\begin{array}{c}\text { Discordo } \\
\text { totalmente }\end{array}$ & Discordo & Indiferente & Concordo & $\begin{array}{c}\text { Concordo } \\
\text { totalmente }\end{array}$ & Total \\
\hline Não Listada & 3 & 7 & 31 & 6 & 2 & $\mathbf{4 9}$ \\
\hline
\end{tabular}




\begin{tabular}{l|l|l|l|l|l|l}
\hline Listada & 1 & 1 & 14 & 19 & 15 & $\mathbf{5 0}$ \\
\hline Total & 4 & 8 & 45 & 25 & 17 & $\mathbf{9 9}$ \\
\hline \multicolumn{7}{l}{} \\
\hline
\end{tabular}

A partir do resultado do teste $\mathcal{X}^{2}$ fornecido pela Tabela 2, de frequência absoluta, para o par de variáveis, pode-se afirmar, para um nível de significância de $5 \%$ e para 4 graus de liberdade, que há relação estatisticamente significante entre as variáveis Presença em Guia e a questão que verifica se os participantes consideram a empresa como boa para se trabalhar. Tais resultados indicam que a manipulação foi efetiva, tanto pela frequência de respondentes que concordaram com a afirmação, quanto pelo teste $\mathcal{X}^{2}$.

Com o intuito de tornar a checagem de manipulação menos óbvia, foram incluídas três perguntas relativas à empresa. A questão número 7 solicitava aos participantes sua concordância com a afirmativa de que a empresa tem responsabilidade socioambiental e a seguinte de que seria confiável, ambas as questões presentes no texto. A questão de número 9 fornecia informação não presente no texto, relativa à responsabilidade fiscal da firma. Devido ao fato de que tais questões estavam presentes de maneira idêntica em todos os questionários (tratamento e controle), esperava-se que não houvesse diferença estatisticamente significante entre as respostas dos grupos de controle e tratamento.

No entanto, verificou-se que a questão sobre confiabilidade da empresa recebeu maior grau de concordância por parte do grupo de tratamento. A quantidade de respondentes do grupo de tratamento que concordou totalmente com a afirmativa foi de 10, e 2 que discordaram, em contrapartida, 2 participantes do grupo de controle concordaram totalmente e 7 discordaram. Tal diferença é significativa conforme o teste $X^{2}$ com 3 graus de liberdade a um nível de significância de 5\% (Pearson $\operatorname{chi}^{2}(3)=8.1554$; $\operatorname{Pr}=0.043$ ). Dado que a questão estava presente nos dois textos, uma possível explicação para que os participantes do grupo de tratamento apresentarem maior concordância com a afirmativa é o spillover effect (LEROY, 2009). Tal efeito pode ter ocorrido como um extrapolamento pela sensação de a empresa constar no guia de melhores para se trabalhar, e assim também afetar a percepção sobre essa outra variável.

\subsection{Teste da Hipótese}

A fim de buscar inferências acerca do comportamento da variável de interesse, propôsse o modelo confirmatório de regressão logística multinomial (1). Uma vez que a variável dependente do estudo é qualitativa e oferece mais de duas possibilidades de resposta (categorias), que são 5 no presente estudo, sendo adequado o uso da regressão logística multinomial para se estimar a probabilidade de ocorrência de cada alternativa (FÁVERO, 2015). Não foram incluídas as variáveis escolaridade e área de formação em virtude da homogeneidade do perfil dos participantes.

$$
p_{i_{m}}=\frac{e^{Z_{i_{m}}}}{\sum_{m=0}^{M-1} e^{Z_{i_{m}}}}
$$

Em que:

$p=$ probabilidade de ocorrência do evento;

$i=$ probabilidade de ocorrência de cada categoria;

$m=$ quantidade de categorias da variável de interesse, em que o número de logitos estimados será $(\mathrm{M}-1)$, e a expressão geral do logito $Z_{i_{m}}(\mathrm{~m}=0,1, \ldots \mathrm{M}-1)$ (Fávero, 2015);

$e=$ logaritmo neperiano;

$Z=\operatorname{logito}\left(\alpha+\beta_{1}\right.$ Presença_guia $+\beta_{2}$ Perfil_investidor $+\beta_{3}$ Sexo $+\beta_{4}$ Idade $)$;

$\sum=$ somatório dos logitos. 
Apresentam-se na Tabela 3 os resultados da regressão. Com base no teste $\chi^{2}$, pode-se inferir que o modelo proposto é adequado à teoria subjacente. Em relação à estatística $z$ de Wald, considerando uma probabilidade de 5\%, nota-se que nenhuma das variáveis em nenhuma das categorias apresenta resultado estatisticamente significante. Dessa maneira, infere-se a partir de tais resultados que nenhuma das variáveis é significante para explicar o percentual investido pelos participantes.

Tabela 3 - Resultados do modelo proposto

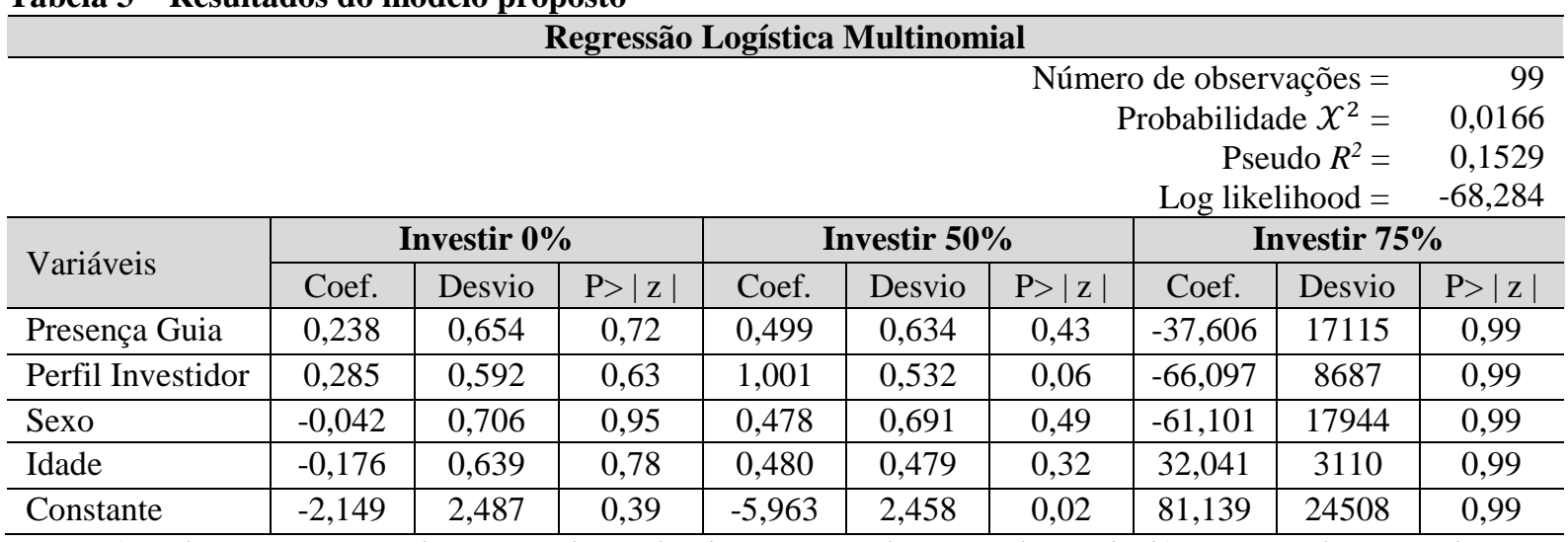

Notas: a) 2 observações completamente determinadas. Erros padrão questionáveis. b) A categoria "Investir 25\%" foi considera como base por ter a maior frequência. A categoria "Investir 100\%" não aparece por não ter sido opção de nenhum dos participantes.

Esses achados confirmam a Hipótese 1, de que a presença em guias não influencia decisões de investimento. Especificamente, para os questionários com tratamento, em nenhuma das categorias de investimento a variável presença em guias apresenta significância. As demais variáveis, em razão da homogeneidade da amostra, também não se apresentam estatisticamente significantes para explicar a probabilidade de escolha das categorias da variável de interesse.

Esse resultado pode demonstrar evidência no sentido de que a informação de que a empresa foi listada nos últimos anos em guias que apresentam empresas com boas práticas com seus empregados não é fator que cause uma decisão de investir mais. Dessa maneira, considerando a Balance Theory, se for negativa a relação de avaliação (aprovação) (CARTWRIGHT; HARARY, 1956) do investidor com relação ao guia, há um estado não balanceado nessa relação que pode levar ao não investimento.

\section{Conclusões}

A partir das evidências empíricas e teoria apresentadas no estudo, convergiu-se para a ideia que as empresas que participam de guias reputacionais podem se utilizar de tal prática como forma de melhoria e promoção de sua imagem junto aos stakeholders. De maneira geral, os achados desta pesquisa confirmam a impressão inicial. Resumidamente, verificou-se que não há relação de causalidade entre o fato de estar listada em guias reputacionais e a tomada de decisão de investimento por parte dos acionistas razoavelmente informados. Desta forma, considerando as teorias da comunicação, principalmente o fato de os grupos terem diferentes níveis de informação no aspecto de reputação, não se observa o efeito do gap knowledge, em um grupo homogêneo e razoavelmente bem informado, de uma informação associada ao comportamento avaliado.

Dessa maneira, destacamos a Balance Theory como uma possível explicação, no sentido de que para os participantes do experimento, um dos seguintes fatores, a fonte (guia 
reputacional) ou a informação (conceito), ou até mesmo os dois, não eram dotados de credibilidade e relevância, respectivamente, para a tomada de decisão.

Há de se considerar que os participantes do experimento, majoritariamente, eram alunos de contabilidade e atuária e possuem o conservadorismo e a familiaridade com indicadores de desempenho e afins como característica. Portanto, este perfil de participante, naturalmente, se utiliza de um número limitado de heurísticas (SOUZA; GUEDES, 2007) a fim de tornar tarefas com um certo grau de complexidade, como a tomada decisão de investimentos, em processos mais simples. Além disso, dados de uma pesquisa do Instituto Rosenfield, encomendado pela BM\&FBovespa em 2012, verificou que apenas $1 \%$ da população brasileira investe em ações, tendo como principais determinantes desconhecimento, falta de dinheiro e aversão ao risco. Finalmente, a diversificação de investimentos se apresenta como estratégia mais eficaz no gerenciamento de ativos. Dessa maneira, o conjunto desses fatores podem se constituir em razoável explicação para a alta concentração dos respondentes na categoria de $25 \%$ de investimento em papeis da empresa sugerida.

A partir do resultado encontrado, podem-se destacar duas principais contribuições. A primeira delas é com relação às empresas participantes do mercado de ações e que são listadas nesses guias relacionados ao ambiente de trabalho, em que esse resultado pode representar um indicativo que informações relacionadas à listagem em tais guias não são relevantes para decisões de possíveis investidores. Outra contribuição pode ser às próprias editoras que publicam tais guias quanto ao seu direcionamento mais voltado às pessoas a busca de emprego, por exemplo.

Como limitações do trabalho, reconhece-se que os modelos estimados são válidos apenas na presença das variáveis utilizadas. Portanto, a inclusão de novas observações, para o caso do modelo exploratório, ou novas variáveis, requerem nova estimação dos parâmetros. Por se tratar de experimento, assume-se menor poder de generalização, em que pese o alto poder de validação interna, ou seja, a assunção de relação causal entre as variáveis estudadas. Para tanto, apresentam-se como sugestões de pesquisas futuras a verificação com traders se há diferente consideração para a indicação de compra de ações de empresas listadas em guias e, em contrapartida, verificar com as empresas quais as razões que as incitam em participar de tais guias.

\section{Referências}

BARNEY, J. Firm resources and sustained competitive advantage. Journal of Management, v. 17, n. 01, p. 99-120, 1991.

BATISTA, L. L.; CAVALHEIRO, R. de F.; LEITE, F. Mídia e referências: um estudo sobre interações e efeitos. Ciências \& Cognição, v. 13, n. 3, p. 151-161, 2008.

BATISTA, L. L. Teorias da Persuasão. In: CITELLI, A.; BERGER, C.; BACCEGA, M. A.; LOPES, M. I. V.; FRANÇA, V.V.(Orgs). Dicionário de comunicação: escolas, teorias e autores. São Paulo: Contexto, 2014.

BECKNELL, J. C.; WILSON, W. R.; BAIRD J. C. The Effect of Frequency of Presentation on the Choice of Nonsense Syllables. The Journal of Psychology, v. 56, n. 1, p. 165-170, 1963.

BERDEJO, L. M. A.; GUERREIRO, R. A participação na lista de empresas com melhores práticas para com os funcionários e seu impacto na performance: um estudo empírico sob a lógica da RBV (Resource-Based View). Faces, v. 8, n 3, p. 87-101, 2009. 
BROWN, J. A. C. Techniques of Persuasion: From Propaganda to Brainwashing. London: Penguin Books, 1963.

CARTWRIGHT, Dorwin; HARARY, Frank. Structural balance: a generalization of Heider's theory. Psychological Review, v. 63, n. 5, p. 277, 1956.

CHENG, Beiting; IOANNOU, Ioannis; SERAFEIM, George. Corporate social responsibility and access to finance. Strategic management journal, v. 35, n. 1, p. 1-23, 2014.

DAWKINS, R.; KREBS, J. R. Animal signals: information or manipulation? In: Krebs, J.R.; Davies, N. B. (eds) Behavioural ecology: an evolutionary approach. Blackwell, Oxford, p. 282309, 1978.

DIAS FILHO, J. M. In. RIBEIRO FILHO, J. F.; LOPES, J.; PEDERNEIRAS, M. (org). Estudando Teoria da Contabilidade. p. 321- 354. São Paulo: Atlas, 2009.

EASLEY, D.; HVIDKJAER, S.; O'HARA, M. Is information risk determinant of asset returns? The Journal of Finance, v. 57, p. 2185-2221, 2002.

EASLEY, D.; KIEFER, N. M.; O'HARA, M.; PAPERMAN, J. B. Liquidity, information, and infrequently traded stocks. The Journal of Finance, v. 51, n. 4, p. 1405-1436, 1996.

ELLIOTT, W. B.; JACKSON, K. E.; PEECHER, M. E.; WHITE, B. J. The unintended effect of Corporate Social Responsibility performance on investors' estimates of fundamental value. Accounting Review, v. 89, n. 1, p. 275-302, 2014. http://doi.org/10.2308/accr-50577

FÁVERO, L. P. Análise de Dados: modelos de regressão com Excel®, Stata® e SPSS®. Rio de Janeiro: Elsevier, 2015.

FÁVERO, L. P. L.; BEFIORE, P. Análise de Dados: Técnicas Multivariadas Exploratórias com SPSS® e Stata®. Rio de Janeiro: Elsevier, 2015.

FOMBRUN, C. J. Indices of Corporate Reputation: An Analysis of Media Rankings and Social Monitors' Ratings. Corporate Reputation Review, v. 1, n. 4, p. 327-340, 1998.

FRYXELL, G. E.; WANG, J. The fortune of 'Reputation' Index: Reputation for what? Journal of management, v. 20, n. 1, p. 1-14, 1994.

FULMER, I. S., GERHART, B.; SCOTT, K. S. Are the 100 best better? An empirical investigation of the relationship between being a "great place to work" and firm performance. Personnel Psychology, v. 56, p. 965-993, 2003. http://doi.org/10.1111/j.17446570.2003.tb00246.x

JUNQUEIRA, E. R.; BISPO, J. DE S.; CALIJURI, M. S. Melhores empresas para os empregados e retorno para o acionista: existe alguma relação? ConTexto, v. 7, n. 12, p. 1-20, 2007.

HARRISON, A.A. A psicologia como ciência social. São Paulo: Cultrix, 1972. 
KACHELMEIER, S. J.; KING, R. R. Using Laboratory Experiments to Evaluate Accounting Policy Issues. Accounting Horizons, v. 16, n. 3, p. 219-232, 2002. http://doi.org/10.2308/acch.2002.16.3.219

KAHNEMAN, D.; TVERSKY, A. Prospect Theory: An Analysis of Decision under Risk. Econometrica, v. 47, n. 2, p. 263-292, 1979. http://doi.org/10.2307/1914185

LEROY, S. Why is it so hard to do my work? The challenge of attention residue when switching between work tasks. Organizational Behavior and Human Decision Processes, v. 109, n. 2, p. 168-181, 2009. http://doi.org/10.1016/j.obhdp.2009.04.002

LIBBY, R.; BLOOMFIELD, R.; NELSON, M. W. Experimental research in financial accounting. Accounting, Organizations and Society, v. 27, n. 8, p. 775-810, 2002. http://doi.org/10.1016/S0361-3682(01)00011-3

LIMA, E. M.; CORRAR, L. J. Comparação de desempenho entre as empresas melhores e maiores apontadas como melhores para trabalhar. Revista de Contabilidade do Mestrado em Ciências Contábeis da UERJ, v. 14, n. 3, p. 27-43, 2009.

MANDEL, N.; JOHNSON, E. J. When web pages influence choice: Effects of visual primes on experts and novices. Journal of Consumer Research, v. 29, n. 2, p. 235-245, 2002.

MASLOW, A. H. A theory of human motivation. Psychological Review, v. 50, n. 4, p. 370396, 1943.

MASLOW, A. H. Motivation and personality. New York: Harper, 1954.

ORLITZKY, M.; SCHMIDT, F. L.; RYNES, S. L. Corporate social and financial performance: a meta-analysis. Organization Studies, v. 24, n. 3, p. 403-441, 2003. http://doi.org/10.1177/0170840603024003910

PERDUE, B. C.; SUMMERS, J. O. Checking the Success of Manipulations in Marketing Experiments. Journal of Marketing Research, v. 23, n. 4, p. 317-326, 1986. http://doi.org/10.2307/3151807

ROBERTS, P. W.; DOWLING, G. R. Corporate reputation and sustained superior financial performance. Strategic Management Journal, v. 23, n. 12, p. 1077-1093, 2002. http://doi.org/10.1002/smj.274

SILVA, D. J. C.; MIRANDA, L. C.; KASSAI, J. R.; ANJOS, L. C. M. Será que "melhores para trabalhar" são também as melhores empresas para os acionistas? Revista de Economia Política e História Econômica, v.9, n. 30, p. 218-243, 2013.

SILVA, J.; BARBOSA, P.; TEIXEIRA, L.; REIS NETO, M. Comportamentos relacionados à decisão de compra de papéis Bovespa: a influência do message framing no pequeno investidor mineiro. Revista Eletrônica de Estratégia \& Negócios, v. 3, n. 2, p. 118-139, 2010

SOUSA, J. P. Elementos de teoria e pesquisa da comunicação e da mídia. Porto: Letras Contemporâneas Oficina Editorial, 2003. 
SOUZA, A. A. L.; GUEDES, A. C. B. Casar ou comprar uma bicicleta. Revista Psique, Edição Especial, 2007.

ZAJONC, R.B. Feeling and thinking: Preferences need no inferences. American Psychologist, v. 35, p. 151-75, 1980.

\section{APÊNDICE - INSTRUMENTO DE COLETA DE DADOS DA PESQUISA}

\section{$\underline{\text { Pesquisa sobre Decisão de Investimento }}$}

Suponha que você recebeu uma herança de um parente distante, no valor de $\mathrm{R} \$ 100.000,00$. Ao procurar seu Banco para depositar o dinheiro, o gerente sugere que você aplique o montante, em ações de uma empresa multinacional americana do setor de eletroeletrônicos, com representação no Brasil. No ano de 2015 a firma obteve vendas de R \$ 3.956,20 (milhões), uma taxa de crescimento de $-5,8 \%$ e um lucro de $\mathrm{R} \$ 763,1$ (milhões). Tem apresentado uma lucratividade média de $20 \%$ nos últimos 5 anos. Por ter ações na bolsa de valores, o balanço e outras demonstrações financeiras daquela empresa são sempre auditados e confiáveis. Além disso, possui boa reputação no mercado e se mostra preocupada em conciliar desenvolvimento econômico e preservação do meio ambiente. Apesar do atual cenário de crise do mercado brasileiro, os balanços parciais sugerem que a tendência de lucro, embora menor que nos anos anteriores, será mantida neste ano.

OBS: adicionalmente, o questionário com tratamento apresentava a seguinte frase:

Por fim, nos últimos 4 anos a empresa tem sido listada, em guias das melhores empresas para se trabalhar no Brasil.

\section{Quanto do valor da herança você estaria disposto a investir em ações daquela empresa:}
( ) $0 \%$
( ) $25 \%$
( ) $50 \%$
( ) $75 \%$
( ) $100 \%$

2. Qual o seu tipo de aplicação financeira preferido?
( ) Poupança
( ) $\mathrm{CDB} /$ Renda Fixa
( ) Ações e Derivativos
( ) Nenhum tipo

3. Qual o seu sexo?
( ) Masculino
( ) Feminino

4. Qual sua faixa etária?
( ) Até 18 anos
( ) Até 40 anos
( ) Até 25 anos
( ) Acima de 40 anos
( ) Até 30 anos

\section{Qual sua escolaridade?}
( ) Superior incompleto
( ) Mestrado / Doutorado (incompleto)
( ) Superior Completo
( ) Mestrado / Doutorado (Completo)
( ) Especialização

6. Qual sua área de formação?
( ) Administração
( ) Economia
( ) Contabilidade
( ) Atuária 

( ) Saúde
( ) Outros

Para as questões de 7 a 10 use a seguinte escala de respostas: 1= Discordo totalmente e 5= Concordo totalmente:

\begin{tabular}{l}
\begin{tabular}{|l|l|l|l|l|l|}
\hline 7. & A empresa tem responsabilidade socioambiental. & $\mathbf{2}$ & $\mathbf{5}$ \\
\hline 8. & A empresa é confiável. & & & & \\
\hline 9. & A empresa tem responsabilidade fiscal & & & \\
\hline 10 & A empresa é boa para se trabalhar. & & & & \\
\hline
\end{tabular} \\
\hline
\end{tabular}

